\title{
Review Article \\ Protein Kinase CK2: A Targetable BCR-ABL Partner in Philadelphia Positive Leukemias
}

\author{
Alessandro Morotti, ${ }^{1}$ Giovanna Carrà, ${ }^{1}$ Cristina Panuzzo, ${ }^{1}$ Sabrina Crivellaro, ${ }^{1}$ \\ Riccardo Taulli, ${ }^{2}$ Angelo Guerrasio, ${ }^{1}$ and Giuseppe Saglio ${ }^{1}$ \\ ${ }^{1}$ Department of Clinical and Biological Sciences, University of Turin, 10043 Orbassano, Italy \\ ${ }^{2}$ Department of Oncology, University of Turin, 10043 Orbassano, Italy \\ Correspondence should be addressed to Alessandro Morotti; alessandro.morotti@unito.it
}

Received 27 October 2015; Accepted 20 December 2015

Academic Editor: Estella M. Matutes

Copyright (C) 2015 Alessandro Morotti et al. This is an open access article distributed under the Creative Commons Attribution License, which permits unrestricted use, distribution, and reproduction in any medium, provided the original work is properly cited.

BCR-ABL-mediated leukemias, either Chronic Myeloid Leukemia (CML) or Philadelphia positive Acute Lymphoblastic Leukemia (ALL), are the paradigm of targeted molecular therapy of cancer due to the impressive clinical responses obtained with BCRABL specific tyrosine kinase inhibitors (TKIs). However, BCR-ABL TKIs do not allow completely eradicating both CML and ALL. Furthermore, ALL therapy is associated with much worse responses to TKIs than those observed in CML. The identification of additional pathways that mediate BCR-ABL leukemogenesis is indeed mandatory to achieve synthetic lethality together with TKI. Here, we review the role of BCR-ABL/protein kinase CK2 interaction in BCR-ABL leukemias, with potentially relevant implications for therapy.

\section{Introduction}

The $t(9 ; 22)$ chromosomal translocation (also known as Philadelphia chromosome, or $\mathrm{Ph}^{+}$) is the genetic hallmark of Chronic Myeloid Leukemia (CML) and characterizes one quarter of adult Acute Lymphoblastic Leukemia (ALL) and less than $5 \%$ of pediatric ALL [1-4]. CML is sustained by the p210-BCR-ABL isoform, while $\mathrm{Ph}^{+}$-ALL is driven by a shorter p190-BCR-ABL isoform [5]. BCR-ABL leukemias are the paradigm of cancer targeted therapy, due to the successful development of BCR-ABL specific tyrosine kinase inhibitors (TKIs). However, $\mathrm{CML}$ and $\mathrm{Ph}^{+}$-ALL still challenge clinicians and biologists. Clinicians are facing the fact that CML is still an uncurable disease [6]. Even if CML is effectively targeted by TKIs with astonishing responses rates, most of those patients that discontinue TKI therapy eventually relapse [7] due to the persistence of TKI resistant CML stem cells [8-11]. The second, $\mathrm{Ph}^{+}$-ALL, is associated with much worse responses to TKI than those observed in CML $[1,12]$ and therefore requires additional targets to achieve synthetic lethality together with TKI. Furthermore, clinicians have also to address the issue of TKI resistance due to the development of BCR-ABL point mutations [13]. Therefore, the definition of those pathways that are necessary for the maintenance of $\mathrm{Ph}^{+}$ leukemias could identify novel targets to achieve synthetic lethality together with TKI. Here, we will review the role of protein kinase CK2 (Casein Kinase 2, CK2 from here on) as a BCR-ABL substrate.

\section{Protein Kinase CK2}

2.1. Biological Characterization. CK2 is an ubiquitously expressed serine-threonine kinase [14-21]. It is composed of two catalytic and two regulator subunits. The catalytic units are represented by the isoforms CK2 $\alpha$ and CK2 $\alpha^{\prime}$; the regulatory unit is composed of the CK2 $\beta$ isoform. Each subunit is the product of different genes. The relevance of CK2 in biological processes is highlighted by the phenotype of CK2 knockout mice. In particular, both CK2 $\alpha[22,23]$ and CK2 $\beta$ [24] knockout mice are lethal with multiple embryonic alterations; however, knockout mice of CK2 $\alpha^{\prime}$ are viable [25], although sterile, suggesting some grade of 


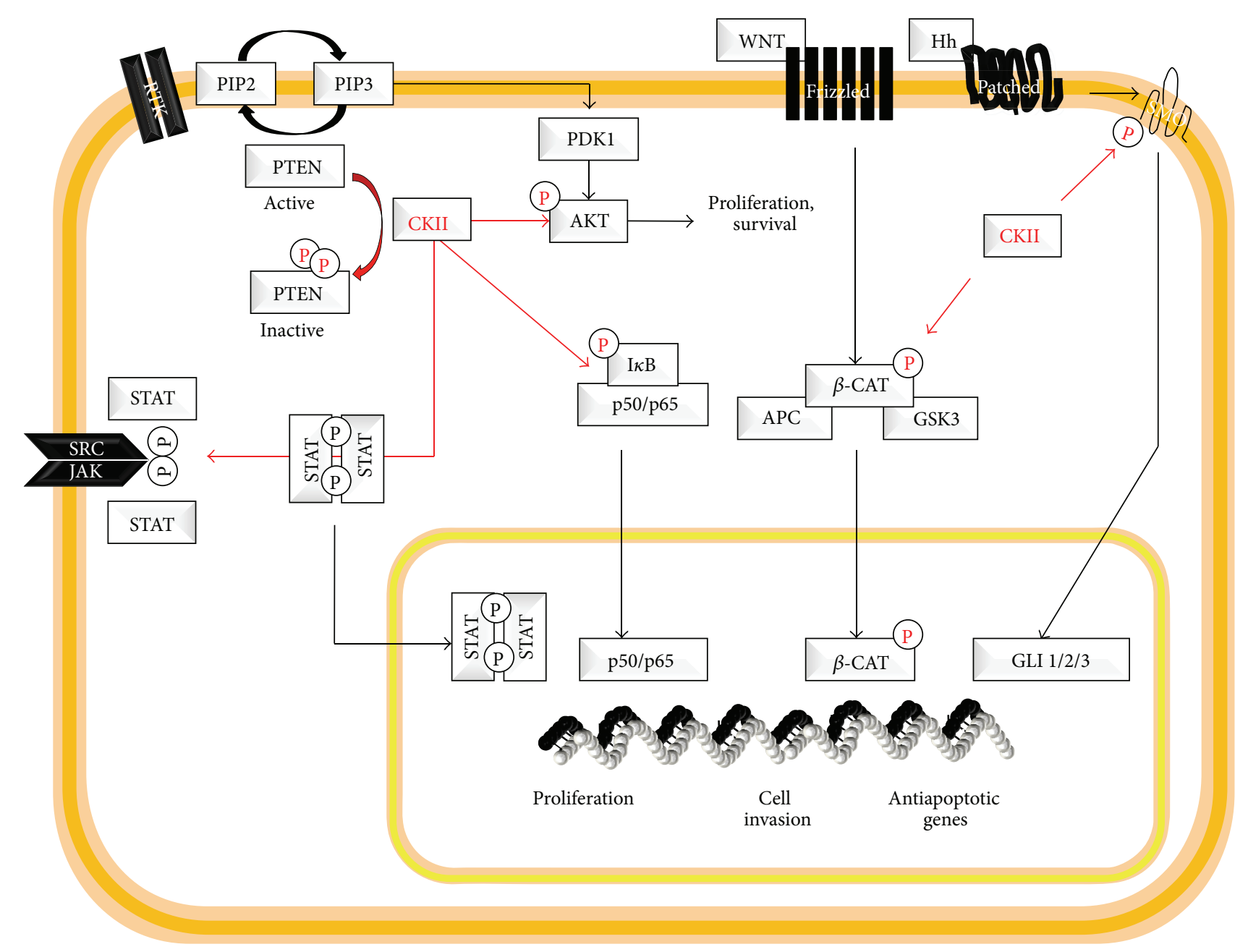

FIGURE 1: Protein kinase CK2 targets. This figure summarizes major CK2 targets.

compensations among the $\mathrm{CK} 2$ catalytic subunits. The CK2 $\beta$ subunit is highly conserved among species and is involved in the assembly of the tetrameric complex with the catalytic subunits and in the modulation of substrate recognition. Two CK2 $\beta$ interact with two identical (two CK2 $\alpha$ or two $\mathrm{CK} 2 \alpha^{\prime}$ ) or nonidentical (one $\mathrm{CK} 2 \alpha$ and one CK2 $\alpha^{\prime}$ ) catalytic subunits. The CK2 kinase is able to phosphorylate serine or threonine residues in proteins bearing a minimal consensus sequence that contains an acidic residue (Glu, Asp, pSer, or pTyr). CK2 is a unique kinase in that it can utilize GTP as well as ATP as the phosphate donor [19]. CK2 was often referred to as a constitutively active kinase, although several reports suggested different chances of kinase modulation [26]. In particular, it was extensively reviewed that CK2 activity can be modulated by changes in the subunit assembly, interaction with different regulatory elements, and protein interaction and finally even through different levels of phosphorylation/autophosphorylation [16, 19, 26, 27]. Several phosphorylation residues have indeed been identified both in the catalytic and regulatory subunits. Even if these phosphorylation sites did not appear to directly affect the kinase activity, these sites could affect the stability of the tetramer and therefore regulate substrate phosphorylation.

2.2. CK2 Targets. Beside the complex mechanisms of CK2 regulation and activation, which still require further investigations, it is well documented that CK2 phosphorylates several different targets, as extensively reviewed [18, 28]. CK2 was discovered in each cellular compartment, from the membrane to the nucleus, suggesting that it can interact and regulate the function of several proteins in every cellular compartment. In particular, CK2 is known to regulate cellular proliferation and apoptosis, DNA damage repair and gene expression, regulation of cell structure, and other cellular processes. Figure 1 shows some of the cancer associated targets, such as AKT, IkB- $\alpha$, STAT5, and $\beta$-catenin.

2.3. CK2 Inactivates PTEN. PTEN is a tumor suppressor that negatively regulates the PI3K-AKT pathway, therefore counteracting one of the major signaling transduction networks involved in cancer pathogenesis $[29,30]$. PTEN function is regulated by several posttransductional modifications 
such as serine/threonine-phosphorylation, acetylation, ubiquitination, and sumoylation [30]. Notably, the C-terminal domain of PTEN contains six serine/threonine residues (Thr-366; Ser-370; Ser-380; Thr-382; Thr-383 and Ser-385) that regulate the activity of the phosphatase PTEN, cellular compartmentalization, and protein stability [31-35]. Even if Ser-370 and Ser-385 were identified by mass-spectrometry as the mostly phosphorylated sites in PTEN [36, 37], all these residues have been described as CK2 substrates. Notably, CK2-mediated PTEN tail phosphorylation was clearly shown to play a role in different Philadelphia chromosome negative leukemias [38-42].

\section{CK2 Inhibitors}

Several CK2 inhibitors have been developed with different grades of selectivity and potency, as extensively reported [17, 43-54]. CK2 inhibitors have already been tested in hematological cancers. In particular, Chronic Lymphocytic Leukemia has been extensively studied for its high sensitiveness to CK2 inhibitors [41, 55]. Similarly, CK2 inhibitors appeared to display important effects in T-ALL [56]. Currently, some clinical trials are ongoing and will assess the relevance of CK2 inhibitors in the setting of hematological and solid cancers.

\section{CK2 in Philadelphia Positive Leukemias}

An original report showed that CK2 is highly expressed in proliferating CML myeloid progenitors [57]. Later, it was shown that BCR-ABL is able to physically interact with CK2 $\alpha$ in K562 cell line, via the ABL portion of the chimeric protein [58]. Similarly, CK2 $\alpha$ was shown to interact with cAbl in NIH3T3 cells. Furthermore, BCR-ABL appeared to phosphorylate CK2 $\alpha$ on tyrosine residues. Notably, in this first report, BCR-ABL was shown to inhibit the function of CK $2 \alpha$ [58]. BCR-ABL/CK2 $\alpha$ interaction was also investigated by another group [59], who demonstrated that CK $2 \alpha$ strongly interacts with the BCR region between amino acids 242 and 413. Oppositely to the first report, CK2 $\alpha$ was shown to positively mediate BCR-ABL signaling in both $\mathrm{CML}$ and $\mathrm{Ph}^{+}$-ALL [59]. Treatment with CK2 $\alpha$ inhibitor 4,5,6,7tetrabromo-2-benzotiazole was indeed shown to inhibit the growth of both p210- and p190-BCR-ABL transformed cells and BCR-ABL positive cells. Notably, the inhibition of BCRABL with TKI is also associated with the reduction of CK2 $\alpha$ serine/threonine kinase activity. These original observations offer important implications for the therapeutical approach of BCR-ABL-positive CML/ALL and for the definition of CK2 regulation mechanisms. In particular, while CK2 has always been referred to as a constitutively active kinase, this work demonstrated that BCR-ABL regulates CK2 kinase activity, even if through a complex yet unknown mechanism. Another report further highlights the utility of targeting CK2 in the setting of BCR-ABL-mediated leukemias and in particular p190-BCR-ABL ALL cells [60]. A great step forward in the understanding of the role of BCR-ABL/CK2 complex was carried out by the group of Donella-Deana [61]. In particular, while the first two reports lead to opposite conclusions, probably due to different cellular context, the last report confirmed that BCR-ABL interacts with CK2 $\alpha$ in CML cells and that this interaction promotes cellular proliferation. Furthermore, this work provided additional insights on the mechanisms of CK $2 \alpha$ regulation by BCR-ABL. In particular, authors have shown that CK2, both CK2 $\alpha$ and CK2 $\beta$, may be upregulated in imatinib-resistance CML cell lines with a consequent increase in the CK2 kinase activity [61]. Notably, no changes on the mRNA levels were observed, clearly suggesting upstream CK2 regulation. This observation, and the previous observation that CK2 $\alpha$ tyrosine phosphorylation by BCR$\mathrm{ABL}$ affects the CK2 kinase activity, suggests that in CML CK2 not only is just a constitutively active kinase but also can be somehow regulated. To further investigate the mechanisms of interaction, authors have also confirmed that BCR-ABL tyrosine phosphorylates CK2 and that this event is not required for the interaction between the two kinases. However, inhibition of CK2 abrogates the interaction. Although these data did not shed light on the complex mechanism of CK2 regulation, it is clear that BCR-ABL is able to force CK2 to modulate proliferation/survival in $\mathrm{Ph}^{+}$leukemias. The authors have indeed clearly confirmed that CK2 inhibitor CX-4945 is able to promote cell death [61]. All these works did not link BCR-ABL/CK2 $\alpha$ interaction with specific CK2 $\alpha$ targets [58-60]. Recently, we have demonstrated that BCRABL/CK $2 \alpha$ promotes serine phosphorylation of PTEN tail [62] (Figure 2). PTEN is found mostly in the cytosol of CML progenitor cells [63] where it is highly phosphorylated by CK2. PTEN tail phosphorylation inhibits its phosphatase activity both in cellular models and in primary CML cells. Interestingly, PTEN mutants, unable to be phosphorylated by $\mathrm{CK} 2 \alpha$, restored the phosphatase activity and were able to promote strong apoptosis induction in CML cells. Altogether, these works demonstrate that BCR-ABL interacts with CK2 $\alpha$ which is in turn tyrosine phosphorylated [58, 59, 61]; BCRABL somehow "activates" CK2 $\alpha$ towards substrates that are involved in the regulation of proliferation and survival. Lastly, BCR-ABL/CK $2 \alpha$ interaction promotes the phosphorylation of PTEN with consequent inactivation of its phosphatase activity [62].

\section{Conclusions}

Since the discovery of the $t(9 ; 22)$ translocation, the Philadelphia chromosome, as the hallmark of CML, this disease has been the paradigm of precision medicine. However, BCRABL targeting with TKI did not allow eradicating both CML and $\mathrm{Ph}^{+}$-ALL, therefore highlighting the need of combinational therapies. In this review, we have summarized the role of CK2 as an essential mediator of BCR-ABL oncogenic signal. The BCR-ABL/CK2 complex is indeed responsible for mediating BCR-ABL induced cellular proliferation and survival. Targeting CK2 with specific inhibitors has been clearly shown to achieve synthetic lethality together with TKI, suggesting that a combinatorial therapy could help in eradicating $\mathrm{Ph}^{+}$leukemias. Finally, the intriguing role of BCR$\mathrm{ABL} / \mathrm{CK} 2$ complex as being able to functionally inactivate the tumor suppressor PTEN may point to a highly effective 


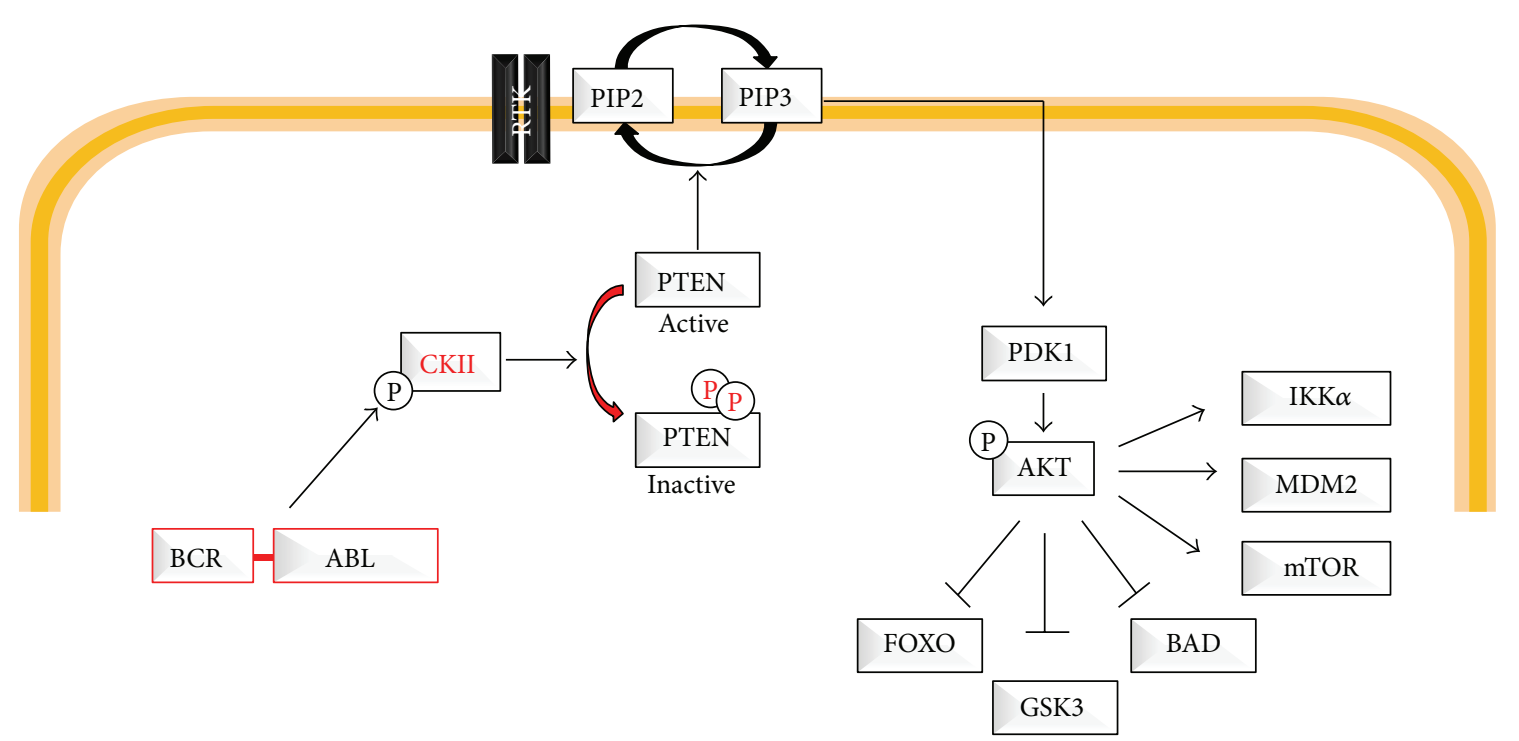

FIGURE 2: BCR-ABL/CK2/PTEN pathway. This figure describes the BCR-ABL/CK2/PTEN pathway.

proapoptotic therapy even in those cases characterized by TKI resistance due to BCR-ABL mutations.

\section{Conflict of Interests}

The authors have no conflict of interests regarding this work.

\section{Authors' Contribution}

Alessandro Morotti wrote the paper; Giovanna Carrà generated the figures; Giovanna Carrà, Cristina Panuzzo, Sabrina Crivellaro, Riccardo Taulli, Angelo Guerrasio, and Giuseppe Saglio reviewed the paper and provided insights.

\section{Acknowledgments}

The authors thank all the members of Professor Saglio laboratory and clinical division and Professor Pier Paolo Pandolfi for insights. This work has been supported by Giovani Ricercatori, GR-2010-2312984, from the Ministero della Salute, Ricerca Finalizzata, to Alessandro Morotti.

\section{References}

[1] E. Maino, R. Sancetta, P. Viero et al., "Current and future management of Ph/BCR-ABL positive ALL," Expert Review of Anticancer Therapy, vol. 14, no. 6, pp. 723-740, 2014.

[2] G. Saglio, A. Morotti, G. Mattioli et al., "Rational approaches to the design of therapeutics targeting molecular markers: the case of chronic myelogenous leukemia," Annals of the New York Academy of Sciences, vol. 1028, pp. 423-431, 2004.

[3] A. Morotti, C. Fava, and G. Saglio, "Milestones and monitoring," Current Hematologic Malignancy Reports, vol. 10, no. 2, pp. 167172, 2015.

[4] J. V. Melo and D. J. Barnes, "Chronic myeloid leukaemia as a model of disease evolution in human cancer," Nature Reviews Cancer, vol. 7, no. 6, pp. 441-453, 2007.
[5] K. M. Bernt and S. P. Hunger, "Current concepts in pediatric Philadelphia chromosome-positive acute lymphoblastic leukemia," Frontiers in Oncology, vol. 4, article 54, 2014.

[6] E. Jabbour and H. Kantarjian, "Chronic myeloid leukemia: 2014 update on diagnosis, monitoring, and management," American Journal of Hematology, vol. 89, no. 5, pp. 547-556, 2014.

[7] K. Sweet and V. Oehler, "Discontinuation of tyrosine kinase inhibitors in chronic myeloid leukemia: when is this a safe option to consider?" Hematology/the Education Program of the American Society of Hematology, vol. 2013, no. 1, pp. 184-188, 2013.

[8] A. Morotti, C. Panuzzo, C. Fava, and G. Saglio, "Kinaseinhibitor-insensitive cancer stem cells in chronic myeloid leukemia," Expert Opinion on Biological Therapy, vol. 14, no. 3, pp. 287-299, 2014.

[9] F. Pellicano, L. Mukherjee, and T. L. Holyoake, "Concise review: cancer cells escape from oncogene addiction: Understanding the mechanisms behind treatment failure for more effective targeting," Stem Cells, vol. 32, no. 6, pp. 1373-1379, 2014.

[10] A. Hamilton, G. V. Helgason, M. Schemionek et al., "Chronic myeloid leukemia stem cells are not dependent on Bcr-Abl kinase activity for their survival," Blood, vol. 119, no. 6, pp. 15011510, 2012.

[11] A. S. Corbin, A. Agarwal, M. Loriaux, J. Cortes, M. W. Deininger, and B. J. Druker, "Human chronic myeloid leukemia stem cells are insensitive to imatinib despite inhibition of BCRABL activity," Journal of Clinical Investigation, vol. 121, no. 1, pp. 396-409, 2011.

[12] A. Hochhaus and H. Kantarjian, "The development of dasatinib as a treatment for Chronic Myeloid Leukemia (CML): from initial studies to application in newly diagnosed patients," Journal of Cancer Research and Clinical Oncology, vol. 139, no. 12, pp. 1971-1984, 2013.

[13] K. Yang and L.-W. Fu, "Mechanisms of resistance to BCR-ABL TKIs and the therapeutic strategies: a review," Critical Reviews in Oncology/Hematology, vol. 93, no. 3, pp. 27-292, 2015.

[14] M. Ruzzene and L. A. Pinna, "Addiction to protein kinase CK2: a common denominator of diverse cancer cells?" Biochimica et 
Biophysica Acta-Proteins and Proteomics, vol. 1804, no. 3, pp. 499-504, 2010.

[15] A. Venerando, M. Ruzzene, and L. A. Pinna, "Casein kinase: the triple meaning of a misnomer," Biochemical Journal, vol. 460, no. 2, pp. 141-156, 2014.

[16] M. Montenarh, “Cellular regulators of protein kinase CK2," Cell and Tissue Research, vol. 342, no. 2, pp. 139-146, 2010.

[17] L. A. Pinna, "Protein kinase CK2: a challenge to canons," Journal of Cell Science, vol. 115, part 20, pp. 3873-3878, 2002.

[18] F. Piazza, S. Manni, M. Ruzzene, L. A. Pinna, C. Gurrieri, and G. Semenzato, "Protein kinase CK2 in hematologic malignancies: Reliance on a pivotal cell survival regulator by oncogenic signaling pathways," Leukemia, vol. 26, no. 6, pp.1174-1179, 2012.

[19] D. W. Litchfield, "Protein kinase CK2: structure, regulation and role in cellular decisions of life and death," Biochemical Journal, vol. 369, no. 1, pp. 1-15, 2003.

[20] R. Battistutta and G. Lolli, "Structural and functional determinants of protein kinase CK2 $\alpha$ : facts and open questions," Molecular and Cellular Biochemistry, vol. 356, no. 1-2, pp. 67-73, 2011.

[21] J. S. Duncan and D. W. Litchfield, “Too much of a good thing: the role of protein kinase CK2 in tumorigenesis and prospects for therapeutic inhibition of CK2," Biochimica et Biophysica Acta, vol. 1784, no. 1, pp. 33-47, 2008.

[22] D. C. Seldin, D. Y. Lou, P. Toselli, E. Landesman-Bollag, and I. Dominguez, "Gene targeting of CK2 catalytic subunits," Molecular and Cellular Biochemistry, vol. 316, no. 1-2, pp. 141147, 2008.

[23] D. Y. Lou, I. Dominguez, P. Toselli, E. Landesman-Bollag, C. O'Brien, and D. C. Seldin, "The alpha catalytic subunit of protein kinase CK2 is required for mouse embryonic development," Molecular and Cellular Biology, vol. 28, no. 1, pp. 131-139, 2008.

[24] T. Buchou, M. Vernet, O. Blond et al., "Disruption of the regulatory $\beta$ subunit of protein kinase CK2 in mice leads to a cell-autonomous defect and early embryonic lethality," Molecular and Cellular Biology, vol. 23, no. 3, pp. 908-915, 2003.

[25] X. Xu, P. A. Toselli, L. D. Russell, and D. C. Seldin, "Globozoospermia in mice lacking the casein kinase II $\alpha^{\prime}$ catalytic subunit," Nature Genetics, vol. 23, no. 1, pp. 118-121, 1999.

[26] D. W. Litchfield, G. Dobrowolska, and E. G. Krebs, "Regulation of casein kinase II by growth factors: a reevaluation," Cellular and Molecular Biology Research, vol. 40, no. 5-6, pp. 373-381, 1994.

[27] K. Niefind and O.-G. Issinger, "Conformational plasticity of the catalytic subunit of protein kinase CK2 and its consequences for regulation and drug design," Biochimica et Biophysica ActaProteins and Proteomics, vol. 1804, no. 3, pp. 484-492, 2010.

[28] O. Filhol and C. Cochet, "Protein kinase CK2 in health and disease: cellular functions of protein kinase CK2: a dynamic affair," Cellular and Molecular Life Sciences, vol. 66, no. 11-12, pp. 1830-1839, 2009.

[29] Y. Shi, B. E. Paluch, X. Wang, and X. Jiang, "PTEN at a glance," Journal of Cell Science, vol. 125, no. 20, pp. 4687-4692, 2012.

[30] M. S. Song, L. Salmena, and P. P. Pandolfi, "The functions and regulation of the PTEN tumour suppressor," Nature Reviews Molecular Cell Biology, vol. 13, no. 5, pp. 283-296, 2012.

[31] S. J. Miller, D. Y. Lou, D. C. Seldin, W. S. Lane, and B. G. Neel, "Direct identification of PTEN phosphorylation sites," FEBS Letters, vol. 528, no. 1-3, pp. 145-153, 2002.

[32] F. Vazquez, S. R. Grossman, Y. Takahashi, M. V. Rokas, N. Nakamura, and W. R. Sellers, "Phosphorylation of the PTEN tail acts as an inhibitory switch by preventing its recruitment into a protein complex," The Journal of Biological Chemistry, vol. 276, no. 52, pp. 48627-48630, 2001.

[33] F. Vazquez, S. Ramaswamy, N. Nakamura, and W. R. Sellers, "Phosphorylation of the PTEN tail regulates protein stability and function," Molecular and Cellular Biology, vol. 20, no. 14, pp. 5010-5018, 2000.

[34] M.-M. Georgescu, K. H. Kirsch, T. Akagi, T. Shishido, and H. Hanafusa, "The tumor-suppressor activity of PTEN is regulated by its carboxyl-terminal region," Proceedings of the National Academy of Sciences of the United States of America, vol. 96, no. 18, pp. 10182-10187, 1999.

[35] J. Torres and R. Pulido, "The tumor suppressor PTEN is phosphorylated by the protein kinase CK2 at its $\mathrm{C}$ terminus. Implications for PTEN stability to proteasome-mediated degradation," Journal of Biological Chemistry, vol. 276, no. 2, pp. $993-$ 998, 2001.

[36] F. Cordier, A. Chaffotte, E. Terrien et al., "Ordered phosphorylation events in two independent cascades of the PTEN C-tail revealed by NMR," Journal of the American Chemical Society, vol. 134, no. 50, pp. 20533-20543, 2012.

[37] L. Odriozola, G. Singh, T. Hoang, and A. M. Chan, "Regulation of PTEN activity by its carboxyl-terminal autoinhibitory domain," The Journal of Biological Chemistry, vol. 282, no. 32, pp. 23306-23315, 2007.

[38] A. Silva, J. A. Yunes, B. A. Cardoso et al., "PTEN posttranslational inactivation and hyperactivation of the PI3K/Akt pathway sustain primary T cell leukemia viability," Journal of Clinical Investigation, vol. 118, no. 11, pp. 3762-3774, 2008.

[39] A. Silva, P. Y. Jotta, A. B. Silveira et al., "Regulation of PTEN by CK2 and Notch1 in primary T-cell acute lymphoblastic leukemia: Rationale for combined use of CK2- and $\gamma$-secretase inhibitors," Haematologica, vol. 95, no. 4, pp. 674-678, 2010.

[40] A. M. Gomes, M. V. D. Soares, P. Ribeiro et al., "Adult B-cell acute lymphoblastic leukemia cells display decreased PTEN activity and constitutive hyperactivation of PI3K/Akt pathway despite high PTEN protein levels," Haematologica, vol. 99, no. 6, pp. 1062-1068, 2014.

[41] L. R. Martins, Y. Perera, P. Lúcio, M. G. Silva, S. E. Perea, and J. T. Barata, "Targeting chronic lymphocytic leukemia using CIGB-300, a clinical-stage CK2-specific cell-permeable peptide inhibitor," Oncotarget, vol. 5, no. 1, pp. 258-263, 2014.

[42] M. Shehata, S. Schnabl, D. Demirtas et al., "Reconstitution of PTEN activity by CK2 inhibitors and interference with the PI3K/Akt cascade counteract the antiapoptotic effect of human stromal cells in chronic lymphocytic leukemia," Blood, vol. 116, no. 14, pp. 2513-2521, 2010.

[43] I. M. Hanif, I. M. Hanif, M. A. Shazib, K. A. Ahmad, and S. Pervaiz, "Casein Kinase II: an attractive target for anti-cancer drug design," International Journal of Biochemistry and Cell Biology, vol. 42, no. 10, pp. 1602-1605, 2010.

[44] G. Cozza, L. A. Pinna, and S. Moro, "Kinase CK2 inhibition: an update," Current Medicinal Chemistry, vol. 20, no. 5, pp. 671693, 2013.

[45] G. Cozza, L. A. Pinna, and S. Moro, "Protein kinase CK2 inhibitors: a patent review," Expert Opinion on Therapeutic Patents, vol. 22, no. 9, pp. 1081-1097, 2012.

[46] G. Cozza, S. Zanin, S. Sarno et al., "Design, validation and efficacy of bisubstrate inhibitors specifically affecting ecto-CK2 kinase activity," Biochemical Journal, vol. 471, no. 3, pp. 415-430, 2015. 
[47] C. Girardi, D. Ottaviani, L. A. Pinna, and M. Ruzzene, "Different persistence of the cellular effects promoted by protein kinase CK2 inhibitors CX-4945 and TDB," BioMed Research International, vol. 2015, Article ID 185736, 9 pages, 2015.

[48] E. Iori, M. Ruzzene, S. Zanin, S. Sbrignadello, L. A. Pinna, and P. Tessari, "Effects of CK2 inhibition in cultured fibroblasts from Type 1 Diabetic patients with or without nephropathy," Growth Factors, vol. 33, no. 4, pp. 259-266, 2015.

[49] G. Cozza, A. Venerando, S. Sarno, and L. A. Pinna, "The selectivity of CK2 inhibitor quinalizarin: a reevaluation," BioMed Research International, vol. 2015, Article ID 734127, 9 pages, 2015.

[50] A. Siddiqui-Jain, D. Drygin, N. Streiner et al., "CX-4945, an orally bioavailable selective inhibitor of protein kinase CK2, inhibits prosurvival and angiogenic signaling and exhibits antitumor efficacy," Cancer Research, vol. 70, no. 24, pp. 1028810298, 2010.

[51] V. Moucadel, R. Prudent, C. F. Sautel et al., "Antitumoral activity of allosteric inhibitors of protein kinase CK2," Oncotarget, vol. 2, no. 12, pp. 997-1010, 2011.

[52] B. Guerra, J. Hochscherf, N. B. Jensen, and O. Issinger, "Identification of a novel potent, selective and cell permeable inhibitor of protein kinase CK2 from the NIH/NCI Diversity Set Library," Molecular and Cellular Biochemistry, vol. 406, no. 1-2, pp. 151161, 2015.

[53] B. Guerra, T. D. L. Rasmussen, A. Schnitzler et al., "Protein kinase CK2 inhibition is associated with the destabilization of HIF-1 $\alpha$ in human cancer cells," Cancer Letters, vol. 356, no. 2, pp. 751-761, 2015.

[54] B. Guerra, M. Fischer, S. Schaefer, and O. Issinger, "The kinase inhibitor D11 induces caspase-mediated cell death in cancer cells resistant to chemotherapeutic treatment," Journal of Experimental \& Clinical Cancer Research, vol. 34, no. 1, article $125,2015$.

[55] R. C. Prins, R. T. Burke, J. W. Tyner, B. J. Druker, M. M. Loriaux, and S. E. Spurgeon, "CX-4945, a selective inhibitor of casein kinase-2 (CK2), exhibits anti-tumor activity in hematologic malignancies including enhanced activity in chronic lymphocytic leukemia when combined with fludarabine and inhibitors of the B-cell receptor pathway," Leukemia, vol. 27, no. 10, pp. 2094-2096, 2013.

[56] F. Buontempo, E. Orsini, L. R. Martins et al., "Cytotoxic activity of the casein kinase 2 inhibitor CX-4945 against T-cell acute lymphoblastic leukemia: targeting the unfolded protein response signaling," Leukemia, vol. 28, no. 3, pp. 543-553, 2014.

[57] F. Phan-Dinh-Tuy, J. Henry, C. Boucheix, J. Y. Perrot, C. Rosenfeld, and A. Kahn, "Protein kinases in human leukemic cells," American Journal of Hematology, vol. 19, no. 3, pp. 209$218,1985$.

[58] J.-K. Hériché and E. M. Chambaz, "Protein kinase CK2 $\alpha$ is a target for the Abl and Bcr-Abl tyrosine kinases," Oncogene, vol. 17, no. 1, pp. 13-18, 1998.

[59] S. Mishra, A. Reichert, J. Cunnick et al., "Protein kinase $\mathrm{CKII} \alpha$ interacts with the Bcr moiety of $\mathrm{Bcr} / \mathrm{Abl}$ and mediates proliferation of Bcr/Abl-expressing cells," Oncogene, vol. 22, no. 51, pp. 8255-8262, 2003.

[60] S. Mishra, V. Pertz, B. Zhang et al., "Treatment of P190 $\mathrm{Bcr} / \mathrm{Abl}$ lymphoblastic leukemia cells with inhibitors of the serine/threonine kinase CK2," Leukemia, vol. 21, no. 1, pp. 178180, 2007.

[61] C. Borgo, L. Cesaro, V. Salizzato et al., "Aberrant signalling by protein kinase CK2 in imatinib-resistant chronic myeloid leukaemia cells: biochemical evidence and therapeutic perspectives," Molecular Oncology, vol. 7, no. 6, pp. 1103-1115, 2013.

[62] A. Morotti, C. Panuzzo, S. Crivellaro et al., "BCR-ABL inactivates cytosolic PTEN through Casein Kinase II mediated tail phosphorylation," Cell Cycle, vol. 14, no. 7, pp. 973-979, 2015.

[63] A. Morotti, C. Panuzzo, S. Crivellaro et al., "BCR-ABL disrupts PTEN nuclear-cytoplasmic shuttling through phosphorylationdependent activation of HAUSP," Leukemia, vol. 28, no. 6, pp. 1326-1333, 2014. 


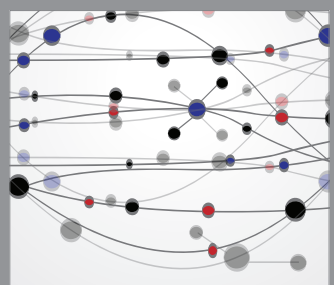

The Scientific World Journal
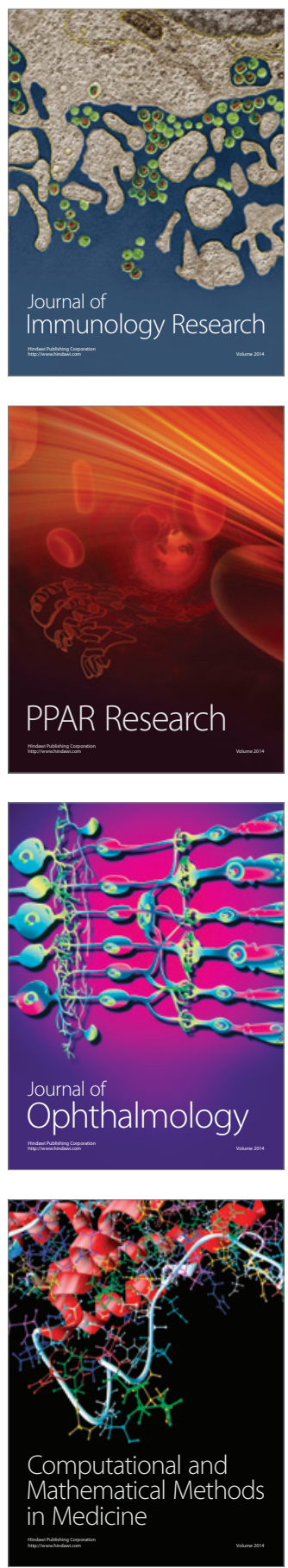

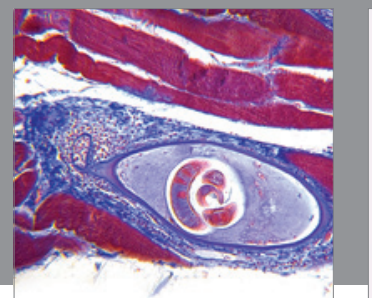

Gastroenterology

Research and Practice
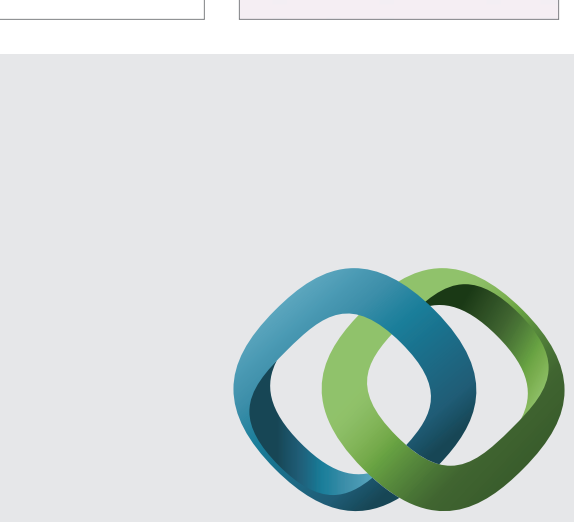

\section{Hindawi}

Submit your manuscripts at

http://www.hindawi.com
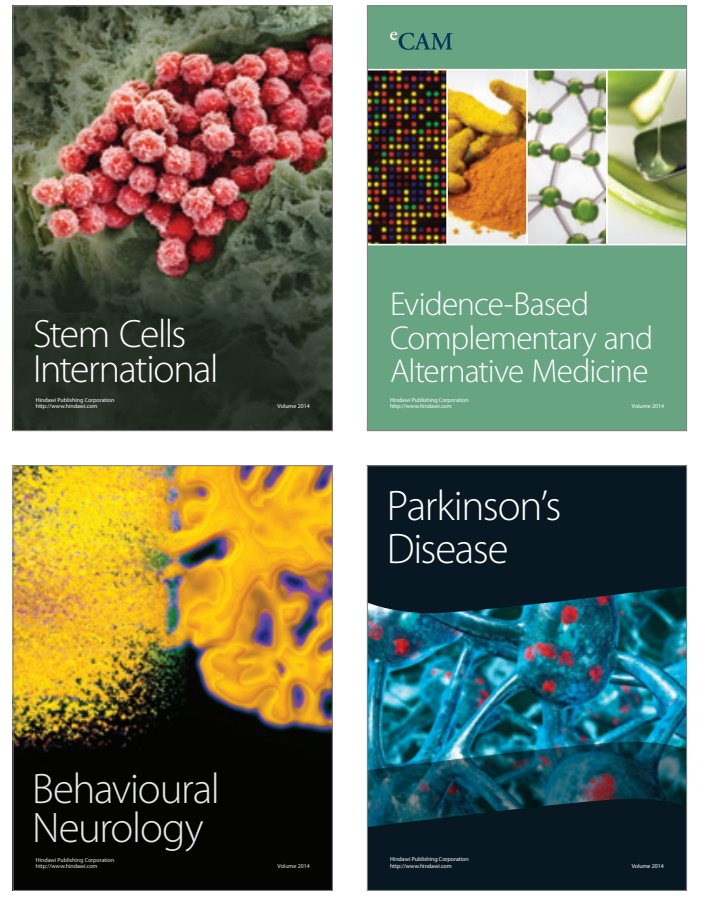
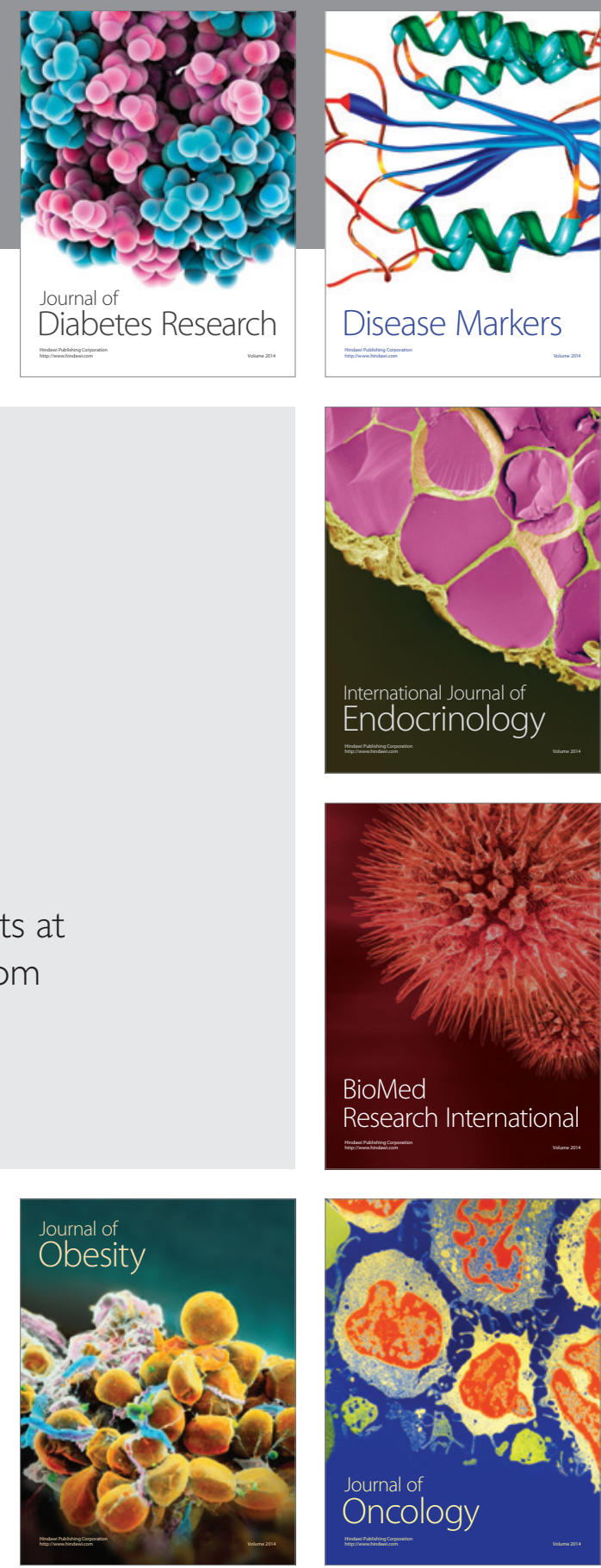

Disease Markers
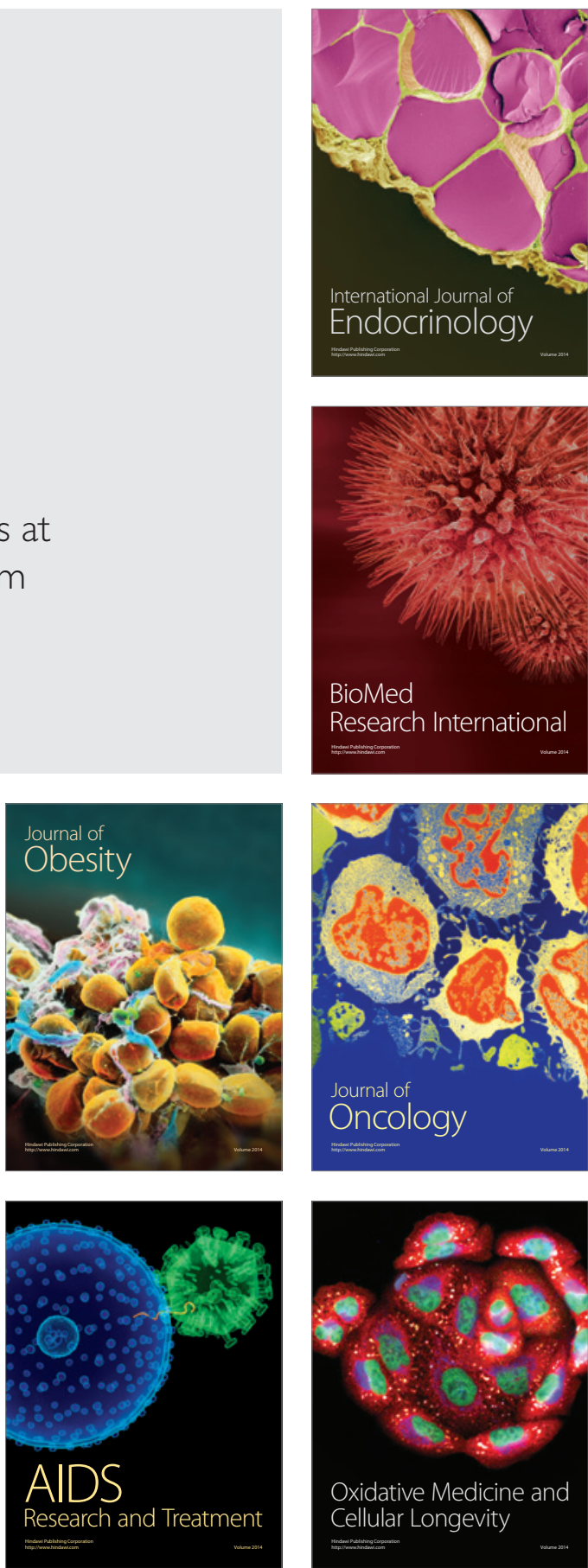